\title{
Sociocognitive and Posttraumatic Models of Dissociation are not Opposed
}

Vedat Sar, M.D.

Professor,

Department of Psychiatry

Istanbul Faculty of Medicine

Istanbul University, Turkey.

President Elect, European Society for Traumatic Stress Studies (ESTSS)

vsar@istanbul.edu.tr

Christa Krüger, M.D.

Professor,

Department of Psychiatry,

University of Pretoria,

South Africa.

Christa.Kruger@up.ac.za

Alfonso Martínez-Taboas, Ph.D.

Associate Professor,

Carlos Albizu University,

San Juan, Puerto Rico.

AMartínez@albizu.edu

Warwick Middleton, M.D.

Adjunct Professor

School of Public Health

Latrobe University

Australia

warmid@tpg.com.au

Martin Dorahy, Ph.D.

Associate Professor,

Department of Psychology,

University of Canterbury,

New Zealand.

martin.dorahy@canterbury.ac.nz

We read the recent review on adult dissociative identity disorder (DID) published in

The Journal of Nervous and Mental Disease (Boysen and VanBergen, 2013) with great

interest. While we welcome this successful effort in documenting the steady research

contributions on DID over the last decade, we want to make the readership clear about two

assumptions of the review which are, in our view, misleading. 
Most saliently, we refute the debate based on the arbitrary polarization of posttraumatic- and sociocognitive models in the etiology of DID. The term "sociocognitive" has generally been associated with the erroneous idea that dissociative disorders are iatrogenic and cultural artifacts, due to socio-cultural and psychotherapeutic influences with suggestible patients and are not related to developmental trauma (Spanos, 1994). In fact, the presence of sociocognitive factors in the development of dissociative processes does not necessarily imply iatrogenesis, as there is an overwhelming literature that clearly indicates that nearly all psychopathological phenomena are ingrained in cultural and societal processes (Bhugra and Bhui, 2007). Therefore, sociocognitive influences need not disqualify from existence any psychiatric disorder, neither should they exclude the role of developmental trauma in the pathogenesis of psychiatric illness. In fact, current research is consistent with the idea that both developmental trauma and dissociative disorders are also usually embedded in socio-cultural contexts and have sociocognitive consequences (Martinez-Taboas, 1991; Krüger, Sokudela, Motlana, Mataboge, and Dikobe, 2007; Sar and Ozturk, 2007; Sar and Öztürk, in press; Sar, Akyüz, Öztürk, and Alioglu, in press; Sar, Middleton and Dorahy, in press). Ironically, the polarization due to a one-sided understanding of the sociocognitive model (as synonymous with iatrogenesis and cultural artifacts) has interfered with more extensive research on socio-cultural factors in the origins of DID and childhood psychological trauma.

Furthermore, Boysen and VanBergen mention a lack of documentation of DID cases outside treatment and use this as evidence for an iatrogenic etiology. In fact, several studies screening for DID, both before and during Boysen and VanBergen's (2013) data window (2000-2010), listed only cases diagnosed as such for the first time (e.g. Akyuz et al., 1999; Dorahy, Mills, Taggart, O’Kane, \& Mulholland, 2006; Sar et al., 2003, 2006; Tutkun et al., 1998), recruited from the general population (e.g. Akyuz et al., 1999), or 
college students (e.g. Sar et al., 2006). In all these studies, the interviewers were blind to the data obtained from probable cases and controls.

There can be no debate about the reality of child trauma and abuse, neither among lay people nor among professionals, because the wide presence of diverse types of childhood trauma across our countries is simply overwhelming. For example, in Australia a Royal Commission on institutional aspects of child sexual abuse was formed at the start of 2013. Proponents for an almost exclusive sociocognitive ('non-posttraumatic') model seemingly never advance a description of what the clinical syndrome typically exhibited by the survivors of corroborated severe inescapable childhood trauma actually is, if it is not indeed a complex trauma syndrome incorporating marked dissociation. Nor do they have an explanation for clinical descriptions of marked dissociation that appear in the old clinical files of some mental health patients who are only much later diagnosed with DID, with file descriptions of florid, and at the time perplexing dissociative phenomena, written by clinicians who clearly had never considered a diagnosis of DID (e.g. Middleton 2004).

We believe that scientific research on DID is not only critical for the future of psychiatry, but also could provide insights into the human condition. Mental health professionals have been familiar with the concepts of identity disturbance, dissociation, and childhood psychological trauma separately for several decades. However, the integration of these interrelated phenomena has lagged behind (for a summary about how trauma affects identity; see Brewin, 2003). We think that an inevitable and necessary intellectual task to deepen our understanding about human existence and suffering is to consider how such divergent variables work together at the individual and collective level. Without understanding DID and its pathophysiological mechanisms (as embedded in socio-cultural 
factors), insight into the links between childhood psychological trauma and clinical psychopathology will never be complete.

\section{References}

Akyüz G, Doğan O, Şar V, Yargıç LI, Tutkun H (1999) Frequency of dissociative identity disorder in the general population in Turkey. Comprehensive Psychiatry, 40: 151-159.

Bhugra D, Bhui K (2007) Textbook of cultural psychiatry. Cambridge University Press, London.

Boysen GA, VanBergen A (2013) A review of published research on adult dissociative identity disorder: 2000-2010. The Journal of Nervous and Mental Disease, 201(1):511.

Brewin CR (2003) A crisis of identity. In: Brewin CR, Posttraumatic stress disorder: malady or myth? Yale University Press, New Haven, pp.63-87.

Dorahy MJ, Mills H, Taggart C, O’Kane M, Mulholland C (2006) Do dissociative disorders exist in the Northern Irish psychiatric population?: A blind diagnosticstructured interview assessment. European Journal of Psychiatry, 20: 172-182.

Krüger C, Sokudela BF, Motlana LM, Mataboge CK, Dikobe AM (2007) Dissociation: A preliminary contextual model. South African Journal of Psychiatry, 13(1): 1321.

Martinez-Taboas A (1991) Multiple personality disorder as seen from a socialconstructionist viewpoint. Dissociation , 4(3):129-133.

Middleton W (2004) The dissociative disorders: a personal "work in progress". 
Australasian Psychiatry, 12(3): 245-252.

Sar V, Akyüz G, Dogan O (2007) Prevalence of dissociative disorders among women in the general population. Psychiatry Research, 149:169-176.

Sar V, Akyuz G, Kugu N, Ozturk E, Ertem-Vehid H (2006) Axis-I dissociative disorder comorbidity of borderline personality disorder and childhood trauma reports. Journal of Clinical Psychiatry, 67(10):1583-1590.

Sar V, Kundakçi T, Kiziltan E, Yargiç IL, Tutkun H, Bakim B, Aydiner O, Özpulat T, Keser V, Özdemir Ö (2003) Axis I dissociative disorder comorbidity of borderline personality disorder among psychiatric outpatients. Journal of Trauma and Dissociation, 4 (1): 119-136.

Sar V, Akyüz G, Öztürk E, Alioglu F (in press) Dissociative depression among women in the community. Journal of Trauma and Dissociation.

Sar V, Öztürk E (2007) Functional dissociation of the self: a sociocognitive approach to trauma and dissociation. Journal of Trauma and Dissociation, 8(4):69-89.

Sar V, Öztürk E (in press) Stimulus deprivation and overstimulation as dissociogenic agents in postmodern oppressive societies. Journal of Trauma and Dissociation.

Sar V, Middleton W, Dorahy MJ (in press) Individual and societal oppression:global perspectives on dissociative disorders. Editorial. Journal of Trauma and Dissociation.

Spanos NP (1994) Multiple identity enactments and multiple personality disorder: a sociocognitive perspective. Psychological Bulletin, 116: 145-165.

Tutkun H, Sar V, Yargiç LI, Özpulat T, Yanik M, Kiziltan E (1998) Frequency of dissociative disorders among psychiatric inpatients in a Turkish university clinic. American Journal of Psychiatry, 155:800-805. 